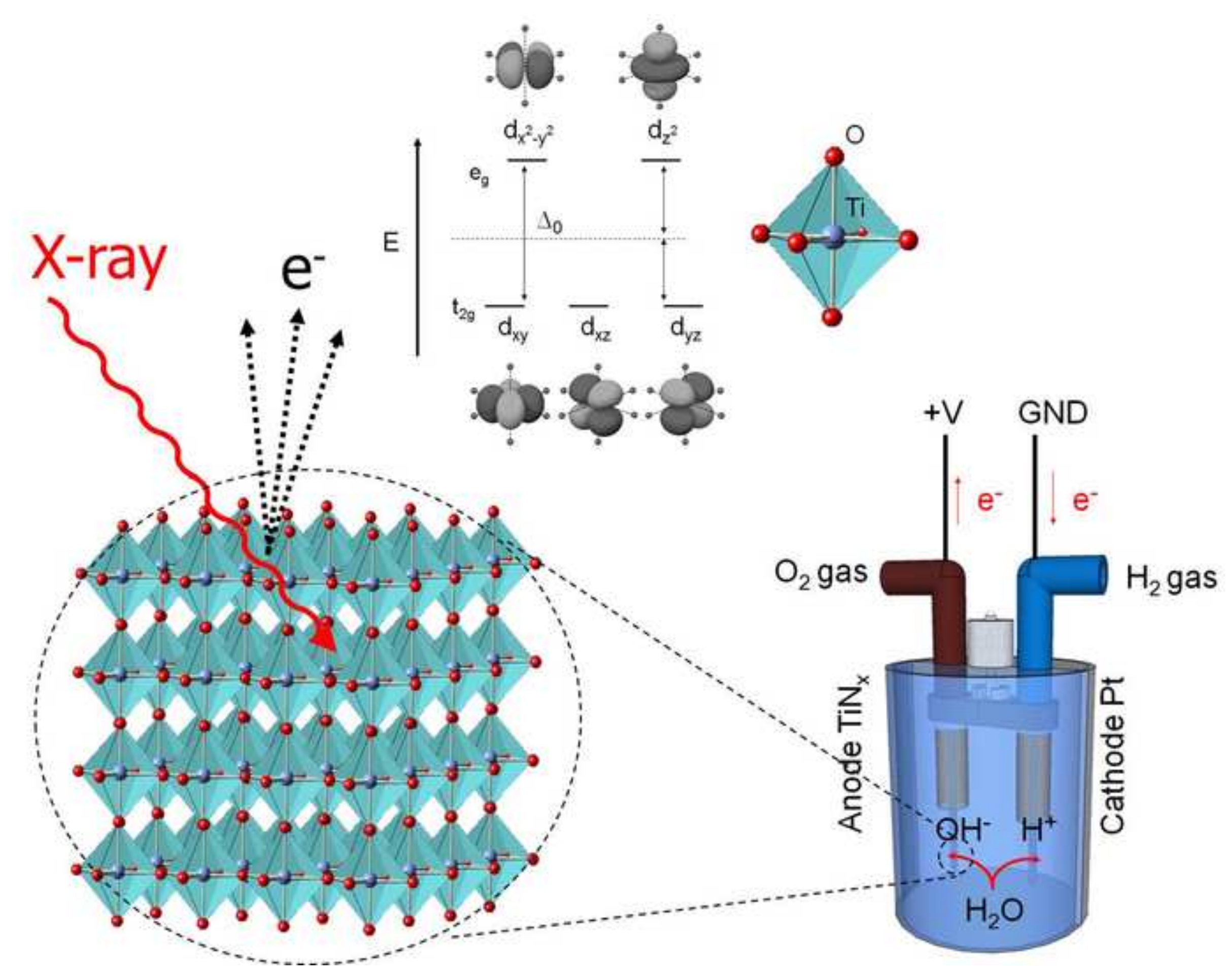




\title{
Exploring the incorporation of nitrogen in titanium and its influence on the electrochemical corrosion resistance in acidic media
}

\author{
J.J. Velasco-Velez ${ }^{1 *}$, B. Davaasuren ${ }^{2}$, M. Scherzer ${ }^{2}$, S. Cap $^{2}$, M. Willinger ${ }^{1}$, J.- \\ H. Guo ${ }^{3}$, R. Schlögl ${ }^{1,2}$, and A. Knop-Gericke ${ }^{2}$ \\ ${ }^{1}$ Max Planck Institute for Chemical Energy Conversion, Mülheim 45470, Germany \\ ${ }^{2}$ Fritz-Haber-Institute of the Max Planck Society, Berlin 14195, Germany \\ ${ }^{3}$ The Advance Light Source, Lawrence Berkeley National Laboratory, Berkeley CA 94720, USA \\ *Corresponding author: velasco@fhi-berlin.mpg.de
}

\begin{abstract}
The role of the nitrogen incorporation into titanium, its chemical nature, the location in the titanium lattice and its electrochemical performance were investigated by a combination of several spectroscopy and microscopy techniques using samples prepared by $\mathrm{CVD}$ of $\mathrm{NH}_{3}$ at different temperatures and successive electrochemically tested in $1 \mathrm{M}$ of $\mathrm{HClO}_{4}$. We found that nitrogen is incorporated in either the interstitial or substitutional site of the lattice depending on the preparation temperature modifying strongly its corrosion resistance which was ascribed to the $\mathrm{N} 2 \mathrm{p}$ hybridization with the Ti $3 \mathrm{~d}$ orbitals. It was found that at low temperature the $\mathrm{N} 2 \mathrm{p}$ orbitals were more likely to hybridize with $\mathrm{Ti}_{3 \mathrm{~d}}-\mathrm{t}_{2 \mathrm{~g}}$ orbitals while higher temperature favours the hybridization with the $\mathrm{Ti}_{3 \mathrm{~d}}-\mathrm{e}_{\mathrm{g}}$ orbitals. This is responsible for the corrosion resistance shown by the samples prepared at higher temperature.
\end{abstract}

\section{Introduction}

There is an increasing effort to use renewable sources of energy because of the social and environmental consequences. However, the energy conversion and/or storage in chemical and electrical energy represent some of the biggest challenges due to the technical complexity [15]. One of the promising directions are electrolyzers which convert the electric energy produced, i.e. by solar cells or wind generators, into chemical energy through, for example, splitting water into oxygen and hydrogen [6-9]. However the cost and the durability of these electrolyzers are their major weaknesses [10-13] due to the low stability and corrosion resistance of the electrode in aggressive media. Precious-metal oxides are the most stable under such conditions, however, these elements are expensive and listed among the rarest on earth, limiting their large-scale application.

Nitrogen incorporation in titanium is a highly interesting subject in electro and photocatalysis due to the long-term durability shown by $\mathrm{TiN}_{\mathrm{x}}$ and the demonstrated ability of nitrogen-doped titanium to absorb visible light $[14,15]$. These properties could be used to produce hydrogen directly from solar light or electrolysis of water into its principal components. One of the most important issues is whether the nitrogen is incorporated by the titanium lattice substitutionally or interstitially [16] modifying its performance as electrode drastically as well as outstanding oxidation behaviors and corrosion resistance $[17,18]$. Although there is a lot of literature [1922] no consensus among the reports on the state of doped nitrogen in $\mathrm{N}-\mathrm{TiO}_{2}$ has been established. A detailed investigation of the thermal reactions between ammonia and titanium will provide valuable information about the related nitrogen incorporation in titanium, which produces the formation of $\mathrm{TiN}_{\mathrm{x}}$ and $\mathrm{TiO}_{\mathrm{x}-2} \mathrm{~N}_{\mathrm{x}}$ from $\mathrm{TiO}_{2}$. In addition, the successive characterization after the prolonged electrochemical conditions will provide information about its performance as an electrolyzer and its corrosion resistance. 
A systematic preparation/characterization scheme has been conducted in this work. $\mathrm{TiN}_{\mathrm{x}}$ samples prepared from the reaction of $\mathrm{NH}_{3}$ with $\mathrm{Ti}$ at different temperatures have been studied with several spectroscopy and microscopy techniques as XPS, NEXAFS, XRD and SEM before and after electrochemical characterization in acidic media. In addition to oxidation state sensitive XPS, bonding geometry sensitive NEXAFS was used to extract local geometry and bonding information. By combining these two techniques we were able to distinguish the formation of nitrogen species and the $\mathrm{N} 2 \mathrm{p}$ hybridization with $\mathrm{Ti}_{3 \mathrm{~d}}$ orbitals as $t_{2 g}$ or $e_{g}$ giving valuable information about the nitrogen incorporation in the lattice. This investigation has given rise to the understanding of the stability of these species as substitutional or interstitial as well as the energy levels that are induced by the incorporation of nitrogen. We found that the interstitial (associated with the hybridization of $\mathrm{N} 2 \mathrm{p}$ and $\mathrm{Ti}$ $3 \mathrm{~d}-\mathrm{t}_{2 \mathrm{~g}}$ orbitals) nitrogen induces doping but lacks stability under electrochemical conditions. On the other hand, substitutional nitrogen (related to the hybridization of $\mathrm{N} 2 \mathrm{p}$ with the Ti $3 \mathrm{~d}-$ $\mathrm{e}_{\mathrm{g}}$ orbitals) leads to doping and higher stability under aggressive electrochemical environments.

\section{Experimental}

The nitrification of pristine Ti foil (Grade 1, $50 \mu \mathrm{m}$ thick from Ankuro International $\mathrm{GmbH}$ ) was carried out using a cold-wall shower-head CVD reactor at the Fritz-Haber-Institute of the Max Planck Society, Berlin. Pre-cut titanium disks, $10 \mathrm{~mm}$ in diameter, were inductively heated at temperatures between $700^{\circ} \mathrm{C}$ to $1100^{\circ} \mathrm{C}$ using a graphite plate as a susceptor. All the reactions were performed under a laminar flow of $10 \%$ ammonia (purity $99.999 \%$ from Westfalen AG) in an argon (200 sccm $\mathrm{NH}_{3}+1800 \mathrm{sccm}$ Ar) gas mixture at 6 mbar pressure for 10 minutes. The incorporation and the chemical state of titanium were monitored by scanning electron microscopy (SEM), X-ray diffraction spectroscopy (XRD), and X-ray photoelectron spectroscopy (XPS). The samples were transferred to the spectrometer by a sealed transfer system in order to avoid contact with ambient environment.

Figure 1a shows the scanning electron microscopy (SEM) images of nitrified titanium foil at different temperatures indicating the samples nitrified at $800^{\circ} \mathrm{C}$ have a similar morphology to the pristine samples. However, it is obvious that the titanium surface morphology is strongly influenced by the nitrogen incorporation as the sample prepared at $1100^{\circ} \mathrm{C}$ shows (see figure 1a3). Chemical analysis was obtained by element specific XPS measurements (see figure $1 \mathrm{~b}$ ). The Ti $2 p$ XP spectra show the spin orbit doublet $2 \mathrm{p} 3 / 2$ and $2 \mathrm{p} 1 / 2$ peaks with an energy separation, $\Delta \mathrm{E}$, of $5.6 \mathrm{eV}$. Titanium presents a peak at $459.2 \mathrm{eV}$ related to $\mathrm{Ti}^{4+}$ which is associated with $\mathrm{TiO}_{2}$, while the peak at $454.9 \mathrm{eV}\left(\mathrm{Ti}^{3+}\right)$ indicates the formation of $\mathrm{TiN}_{\mathrm{x}}$. Finally the peak at $457.2 \mathrm{eV}$ is usually related to a lack of stoichiometry of $\mathrm{TiO}_{2}-\mathrm{TiN}_{\mathrm{x}}$ species with mix oxidation $3+$ and $4+$ states resulting from the formation of $\mathrm{TiO}_{\mathrm{x}-2} \mathrm{~N}_{\mathrm{x}}$ [23]. Thus, the pristine Ti foil features a sharp $\mathrm{Ti}^{4+}$ peak resulting from the native oxide. On the other hand, the sample produced from $\mathrm{NH}_{3}$ at $800^{\circ} \mathrm{C}$ shows an increase in the $\mathrm{TiO}_{\mathrm{x}-2} \mathrm{~N}_{\mathrm{x}}$ species. Samples nitrified at higher temperatures produced significant reduction of $\mathrm{Ti}^{4+}\left(\mathrm{TiO}_{2}\right)$ into $\mathrm{Ti}^{3+}\left(\mathrm{TiN}_{\mathrm{x}}\right)$ as the spectra prove. This interpretation was corroborated by the successive analysis of $\mathrm{N}_{1 \mathrm{~s}}$ and $\mathrm{O}$ 1s XPS spectra. The O 1s XPS spectra of nitrified titanium samples features a dominant peak at $530.6 \mathrm{eV}$, depending on the temperature, which is associated with the presence of $\mathrm{TiO}_{2}$ [17]. The peak at $530.6 \mathrm{eV}$ decreases and an additional peak at $533.3 \mathrm{eV}$ assigned to $\mathrm{NO}_{\mathrm{x}}$ [24] species emerges in samples nitrified at $800^{\circ} \mathrm{C}$. The samples produced at higher temperature yield a decrease in the oxygen species which agrees with the increase in the $\mathrm{Ti}^{3+}$ species shown in $\mathrm{Ti}_{2 p}$ spectrum. The chemical states of the incorporated nitrogen were 
characterized by the $\mathrm{N}_{1 \mathrm{~s}}$ core-level spectra. Based on the binding energies, the $\mathrm{N}_{1 \mathrm{~s}}$ peaks can be divided into two groups: those at binding energy $397.0 \mathrm{eV}$ and at $400.5 \mathrm{eV}$, which are assigned to TiN-like nitrogen species in the lattice and bound to various surface oxygen sites $\left(\mathrm{NO}_{\mathrm{x}}\right.$ like species), respectively [25]. According to this assignment, the $\mathrm{N} 1 \mathrm{~s}$ XP spectra show an increase in the $\mathrm{TiN}_{\mathrm{x}}$ species with increasing nitrification temperature in good agreement with the Ti $2 \mathrm{p}$ and $\mathrm{O} 1 \mathrm{~s}$ spectra. The binding energies and chemical states associated with each orbital are summarized in Table 1.

In addition, the incorporation of nitrogen in titanium was investigated by XRD, which was performed under out-of-plane grazing incidence geometry (with a Goebel mirror and secondary sollers) at a Bruker D8 Advance (Da Vinci - Design with LynxEye detector), equipped with an eulerian cradle. The incident angle was set to $0.4^{\circ}$ Theta and phase analysis was done with DIFFRAC.EVA software from Bruker (Database PDF 2013). Figure 2 show the XRD diagram of pristine, nitrified Ti samples at $800^{\circ}$ and $1100^{\circ} \mathrm{C}$ samples. Prisitine samples behave a titanium oxide character as the reflection peaks at $42.2^{\circ}, 43.2^{\circ}$ and $49^{\circ}$ indicates, see figure $2 a$. Otherwise, figure $2 b$ shows the XRD spectra of samples nitrified at $800^{\circ} \mathrm{C}$ which features a strong peak associated with the presence of $\mathrm{TiN}_{0.26} / \mathrm{TiN}_{0.17}$ species. Finally, samples nitrified at $1100^{\circ} \mathrm{C}$ yieals peaks at $39.3^{\circ}$ and $40.8^{\circ}$ related to to $\mathrm{Ti}_{2} \mathrm{~N}$ species (see figure $2 \mathrm{c}$ ) which is ascribed to the formation of a titanium nitride layer. The elimination of the features ascribed to $\mathrm{TiO}_{2}$ in the pristine sample at $42.2^{\circ}$ and $49^{\circ}$ are due to nitrogenation, which is connected to the formation of $\mathrm{TiO}_{\mathrm{x}-2} \mathrm{~N}_{\mathrm{x}}\left(\mathrm{Ti}^{4+} / \mathrm{Ti}^{3+}\right)$ from $\mathrm{TiO}_{\mathrm{x}}\left(\mathrm{Ti}^{4+}\right)$ species as the XPS proved.

The role and stability of the incorporated nitrogen can be discussed further through a comparison before and after electrochemical reactions carried out under chronoamperometry (CA) control at $+1.0 \mathrm{~V}$ vs $\mathrm{Ag} / \mathrm{Cl}$ (reference electrode) and $\mathrm{Pt}$ (counter electrode) during 30 hours in $1 \mathrm{M}$ of $\mathrm{HClO}_{4}$. In figure 3 the $\mathrm{CV}$ and the $\mathrm{CA}$ of pristine, nitrified Ti foil at $800^{\circ} \mathrm{C}$ and $1100^{\circ} \mathrm{C}$ are shown. SEM and energy dispersive X-ray (EDX) measurements after the electrochemical test shows the corrosion of the pristine Ti foil as shown by the change in oxygen signal. Samples nitrified at $800^{\circ} \mathrm{C}$ suffers less severe corrosion or the adsorption of clusters on the surface activated by bias potential than the pristine samples as seen in samples nitrified at $1100^{\circ} \mathrm{C}$ yield higher resistance to corrosion in aggressive medium under anodic oxidation conditions as seen in EDX. However, EDX is not enough to describe the complex electronic structure of such electrodes before and after the anodic oxidation. Consequently, in depth X-ray spectroscopy (XPS/NEXAFS) measurements were performed at the ISISS beamline in BESSY II (Helmholtz-Zentrum Berlin) using soft X-ray radiation provided from the tuneable monocromator light source. The measurements were made at $\sim 10^{-8}$ mbar using the Fritz-Haber-Institute end station. The kinetic energy was set to $150 \mathrm{eV}$ for the XPS measurements yielding an electron mean free path of about $\sim 0.85 \mathrm{~nm}$ providing surface sensitive spectra. The X-ray absorption spectroscopy (XAS) measurements were recorded in total electron yield (TEY) collecting the secondary electrons by grounding the sample with a current pre-amplifier and has a slightly higher information depth than XPS. The energy resolution was $0.1 \mathrm{eV}$. The possible contamination contribution of atmospheric oxygen was suppressed by the use of an special sealed vacuum transfer system. In addition, no beam damage was detected as confirmed by the successive measurements at the same point. The spectra were normalized to the adsorption pre- and post-edges.

\subsection{XPS analysis}

Figure 3 shows the electrochemical characterization recorded using the prisitine and nitrified $\mathrm{Ti}$ foil used as working electrodes. Measurements were performed during 30 hours CA 
control at $+1.0 \mathrm{~V}$ vs $\mathrm{Ag} / \mathrm{Cl}$ and $\mathrm{Pt}$ counter electrodes in $1 \mathrm{M}$ of $\mathrm{HClO}_{4}$. Figure 4 displays the $\mathrm{XP}$ spectra of $\mathrm{Ti} 2 \mathrm{p}, \mathrm{O}$ 1s and $\mathrm{N}$ 1s core levels before and after the electrochemical characterization. Thus, $\mathrm{Ti}_{2 \mathrm{p}}$ features three peaks of interest at $459.2 \mathrm{eV}, 457.2 \mathrm{eV}$ and 454.9 $\mathrm{eV}$ which are assigned to $\mathrm{Ti}^{4+}\left(\mathrm{TiO}_{2}\right), \mathrm{TiO}_{\mathrm{x}-2} \mathrm{~N}_{\mathrm{x}}$ and $\mathrm{Ti}^{3+}\left(\mathrm{TiN}_{\mathrm{x}}\right)$, respectively (see figure $4 \mathrm{a}$ ). The energy separation between the peaks $2 \mathrm{p} 3 / 2$ and $2 \mathrm{p} 1 / 2$ is $\Delta=5.6 \mathrm{eV}$. Prior to the electrochemical characterization the pristine Ti shows (figure 4a1) an intense peak at 459.2 eV pointing to its $\mathrm{TiO}_{2}$ nature. After the electrochemical characterization the sample remains unaltered as shown in figure $4 \mathrm{a} 2$. On the other hand, samples prepared at $800^{\circ} \mathrm{C}$ feature a characteristic peak at $457.2 \mathrm{eV}$ revealing its $\mathrm{TiO}_{\mathrm{x}-2} \mathrm{~N}_{\mathrm{x}}$ nature (figure $4 \mathrm{a} 3$ ). These species are not stable as the curve in figure $4 \mathrm{a} 4$ indicates: the original $\mathrm{TiO}_{2}$ nature is recovered after the CA control. Finally, the samples prepared at $1100^{\circ} \mathrm{C}$ feature an intense peak at $454.9 \mathrm{eV}$ associated with the formation of $\mathrm{Ti}^{3+}$ (figure 4a5). These species are more stable in aggressive media as the remaining peak at $454.9 \mathrm{eV}$ after $\mathrm{CA}$ indicates (figure 4a6).

Figure $4 \mathrm{~b}$ shows the $\mathrm{O} 1 \mathrm{~s}$ spectra featuring four regions of interest: $\mathrm{TiO}_{2}$ species located at $530.6 \mathrm{eV}$ [26], $\mathrm{TiO}_{\mathrm{x}-2} \mathrm{~N}_{\mathrm{x}} / \mathrm{NO}$ species at $531.4 \mathrm{eV}$ indicating nitrogen incorporation [24], $\mathrm{O}_{2} / \mathrm{H}_{2} \mathrm{O}$ species at $532.5 \mathrm{eV}$ [27] and adsorbed $\mathrm{NO}_{\mathrm{x}}$ species at $533.3 \mathrm{eV}$ [28]. The pristine foil has $\mathrm{TiO}_{2}$ nature as indicates the dominant peak at $530.6 \mathrm{eV}$, which reamains unaltered after the $\mathrm{CA}$ (see figures $4 \mathrm{~b} 1$ and $4 \mathrm{~b} 2$ ). Otherwise, Ti foil nitrified from $\mathrm{NH}_{3}$ at $800^{\circ} \mathrm{C}$ yields two main peaks located at $530.6 \mathrm{eV}$ and $533.3 \mathrm{eV}$ ascribed to $\mathrm{TiO}_{2}$ and $\mathrm{NO}_{\mathrm{x}}$ bonding to surface species [29] (see figure 4b3). After the $\mathrm{CA}$ the adsorbed $\mathrm{NO}_{\mathrm{x}}$ nearly vanished and a peak assigned to $\mathrm{O}_{2} / \mathrm{H}_{2} \mathrm{O}$ species evolved (see figure $4 \mathrm{~b} 4$ ). Nevertheless, samples prepared at $1100^{\circ} \mathrm{C}$ features residual $\mathrm{TiO}_{2}$ character (see figure $4 \mathrm{~b} 4$ ) with a shoulder at $531.4 \mathrm{eV}$ characteristic of $\mathrm{TiO}_{\mathrm{x}-2} \mathrm{~N}_{\mathrm{x}}$ species. The CA control yields the formation of $\mathrm{TiO}_{2}$ and the adsorption $\mathrm{O}_{2} / \mathrm{H}_{2} \mathrm{O}$ species (see figure 4b6).

The $\mathrm{N}$ 1s (figure 4c) spectra show three peaks associated to $\mathrm{TiO}_{\mathrm{x}-2} \mathrm{~N}_{\mathrm{x}}(396.5 \mathrm{eV})$, $\mathrm{TiNx}(397.0$ $\mathrm{eV}$ ) and $400.5 \mathrm{eV}$ related to the presence of $\mathrm{TiO}_{\mathrm{x}-2} \mathrm{~N}_{\mathrm{x}}$ species [24]. Pristine samples (figure $4 \mathrm{c} 1$ and $4 \mathrm{c} 2$ ) do not show the presence of nitrogen. Otherwise, samples prepared at $800^{\circ} \mathrm{C}$ feature two peaks at $396.5 \mathrm{eV}$ and $400.5 \mathrm{eV}$ characteristic of $\mathrm{TiO}_{\mathrm{x}-2} \mathrm{~N}_{\mathrm{x}}$ and $\mathrm{NO}_{\mathrm{x}}$, respectively (figure 4c3). After the CA control the $\mathrm{NO}_{\mathrm{x}}$ species decreased in samples prepared at $800^{\circ} \mathrm{C}$ while the $\mathrm{TiO}_{2-\mathrm{x}} \mathrm{N}_{\mathrm{x}}$ species vanished (figure 4c4). Samples produced at $1100^{\circ} \mathrm{C}$ yielded one main peak at $396.5 \mathrm{eV}$ with a shoulder at $397.0 \mathrm{eV}$ associated to $\mathrm{TiN}_{\mathrm{x}}$ species (see figure $4 c 5)$. After the electrochemical characterization these species remained stable with a slight increase of the peak associated to the $\mathrm{TiO}_{\mathrm{x}-2} \mathrm{~N}_{\mathrm{x}}$ species.

Figure 5 shows the valence band of these samples collected before and after the electrochemical test. It is well known that the incorporation of nitrogen creates a large concentration of vacancies inducing noticeable doping [30]. This is the so-called red shift effect due to the ability of $\mathrm{TiN}_{\mathrm{x}}$ to absorb visible light. Therefore, a carefully investigation of the valence band can elucidate the role of the $\mathrm{N}$ incorporation in the doping of titanium [25]. Figure 5a shows the valence band measurements of the samples before the electrochemical test. Pristine samples show an estimated gap of $3.2 \mathrm{eV}$ referred to the Fermi level position (figure 5a1). On the other hand the nitrification of the titanium samples at $800^{\circ} \mathrm{C}$ and $1100^{\circ} \mathrm{C}$ with $\mathrm{NH}_{3}$ induces the formation of additional energy levels which narrow the gap yielding gaps of $2.4 \mathrm{eV}$ and $2.0 \mathrm{eV}$ respectively. After the electrochemical test the band remained the same for the pristine samples $3.2 \mathrm{eV}$ (figure 5b1) while for the two nitrified samples they increased to $2.5 \mathrm{eV}$ and $2.9 \mathrm{eV}$, respectively (figure $5 \mathrm{~b} 2$ and $5 \mathrm{~b} 3$ ). The XPS measurements indicated a decrease in the $\mathrm{Ti}^{3+}$ and the increase in the $\mathrm{Ti}^{4+}$ species which is ascribed to the formation at the interface of $\mathrm{TiO}_{\mathrm{x}-2} \mathrm{~N}_{\mathrm{x}}$ and $\mathrm{TiO}_{\mathrm{x}}$ species. This fact explains the broader gap observed in the nitrified samples after the electrochemical test. 


\subsection{NEXAFS analysis}

The complex structure of the Ti L-edge NEXAFS spectra of $\mathrm{TiO}_{2}$ is due to the combination of atomic interaction and crystal field effects as a result of the static electric field produced by the surrounding anion neighbors (charge distribution) [31]. The interaction between the ligands and the transition metal is caused by the attraction of positively charge metal cations and non-bonding electrons of the ligands [32]. It follows the change in energy in the transition metal d-orbitals when they are surrounded by an array of ligand charges because some of them will be closer to the d-orbitals. The electrons in the d-orbitals and those in the ligand repel each other by means of electrostatics repulsion between charges. It implies that the delectrons closer to the ligand present higher bond energy than the others resulting in d-orbital energy splitting $\left(\mathrm{t}_{2 \mathrm{~g}}\right.$ and $\mathrm{e}_{\mathrm{g}}$ ) [33] yielding larger separations at higher oxidation states (see figure 6). Figure 7 shows the XA spectra collected in TEY of $\mathrm{TiN}_{\mathrm{x}}$ films produced at different temperatures under the presence of $\mathrm{NH}_{3}$ in the $\mathrm{CVD}$ reactor.

The Ti L-edges XAS-TEY spectrum of reference pristine Ti foil samples are shown in figure 7a1. The $\mathrm{L}_{3}$ region corresponds to the transition $\mathrm{O} 2 \mathrm{p} 3 / 2-\mathrm{Ti} 3 \mathrm{~d}$ and the $\mathrm{L}_{2}$ to $\mathrm{O} 2 \mathrm{p} 1 / 2-\mathrm{Ti} 3 \mathrm{~d}$ [34]. Both bands features a crystal field splitting of the $3 d$ band into $t_{2 g}$ and $e_{g}$. Since $e_{g}$ orbitals are pointed directly toward the $2 \mathrm{p}$ orbitals surrounding $\mathrm{O}$ atoms, this band is sensitive to the local environment. After the electrochemical test the sample features the same behaviour (see figure 7a2) as the subtraction of spectrum 1 from spectra 2 confirms. The $\mathrm{Ti}_{2 \mathrm{p}}$ XAS on samples produced by the nitrification with $\mathrm{NH}_{3}$ at $800^{\circ} \mathrm{C}$ is similar to that of the $\mathrm{TiO}_{2}$ suggesting the influence of $\mathrm{N}$ on $\mathrm{Ti}$ is limited (figure 7a3). It indicates that Ti remains highly oxidized with a small amount of bound nitrogen. After the CA control the samples prepared at $800^{\circ} \mathrm{C}$ feature a slight increase in the $t_{2 g}$ peak intensity (see figure $7 \mathrm{a} 4-3$ ). Samples produced at higher temperature feature broader $t_{2 \mathrm{~g}}$ and $\mathrm{e}_{\mathrm{g}}$ peaks as a result of the lower oxidation state $\left(\mathrm{Ti}^{3+}\right)$ and is corroborated by the XP spectra. One small difference is visible: the energy splitting for the centre of $\mathrm{Ti}_{2 \mathrm{~g}}-\mathrm{e}_{\mathrm{g}}$ at the $\mathrm{L}_{3}$ edge is smaller in $\operatorname{TiN}_{\mathrm{x}}(1.1$ $\mathrm{eV}$ ) than in $\mathrm{TiO}_{2}(1.6 \mathrm{eV})$ (figure 7a5). The splitting between the $\mathrm{t}_{2 \mathrm{~g}}$ and $\mathrm{e}_{\mathrm{g}}$ is smaller for the samples with smaller concentration of oxygen atoms pointing out the presence of reduced $\mathrm{Ti}$ atoms. This fact is proved by the the lower oxidation state $\left(\mathrm{Ti}^{3+}\right)$ observed in the XPS. In addition, samples prepared at higher temperature feature unaltered spectra after the CA control due to the higher stability of the incorporated nitrogen at this temperature.

The O K-edge XA spectra are shown in figure 7b. For pristine Ti foil (figure 7b1) the first doublet located at $531 \mathrm{eV}$ and $534 \mathrm{eV}$ correspond to the $\mathrm{O} 2 \mathrm{p}$ states hybridized with the empty split $\mathrm{Ti}_{3 \mathrm{~d}}$ bands, $\mathrm{t}_{2 \mathrm{~g}}$ and $\mathrm{e}_{\mathrm{g}}$ [35]. The sharpness of these two peaks reflects high ionic or covalent bonding between the $\mathrm{O}$ and Ti. The peaks between $537 \mathrm{eV}$ and $550 \mathrm{eV}$ are due to the delocalized antibonding $\mathrm{O}_{2 \mathrm{p}}$ states coupled to $\mathrm{Ti}_{4 \mathrm{sp}}$ with principally $\mathrm{O} 2 \mathrm{p}$ character. The origin for the $\sigma^{*}$ bands are related to the Ti $2 p, 4 s$ and $4 p$ states hybridized with the $\mathrm{O} 2 \mathrm{p}$ orbitals [36]. The pristine film features the same spectrum after the electrochemical test indicating that the sample remains oxidized with its $\mathrm{TiO}_{2}$ nature (figure $7 \mathrm{~b} 2$ ). Samples prepared at $800^{\circ} \mathrm{C}$ show the peaks merge to a sharp $\mathrm{e}_{\mathrm{g}}$ peak and form a new peak at $533.6 \mathrm{eV}$ in the shoulder (figure $7 \mathrm{~b} 3$ ). The Ti $\mathrm{e}_{\mathrm{g}}$ orbitals, directed towards the oxygen, show stronger coupling with the O $2 p$. Nevertheless, an increment of the peak intensities in the oxygen edge corresponding to the antibonding $\mathrm{O} 2 \mathrm{p}$ transition was observed and is probably associated with a smaller Ti-O interaction. After the $\mathrm{CA}$, the samples prepared at $800^{\circ} \mathrm{C}$ recovered the $\mathrm{t}_{2 \mathrm{~g}}$ and $\mathrm{e}_{\mathrm{g}}$ torbitals characteristic of $\mathrm{TiO}_{2}$ species. While we can confirm this fact for single crystal $\mathrm{TiO}_{2}$, the width and asymmetry requires the inclusion of a third peak near $\mathrm{e}_{\mathrm{g}}$ for a correct deconvolution 
(figure 7b4) [37]. Finally samples prepared at higher temperature features residual oxygen resembles slightly the $\mathrm{TiO}_{2}$ spectrum (figure 7b5). These features are likely related to the formation of residual surface $\mathrm{TiO}_{2}$. After the CA control the sample remains unaltered as confirmed by the residual presence of oxygen (figure $7 \mathrm{~b} 6$ ).

Figure 7c shows the $\mathrm{N}$ K-edge spectra, the first two spectral features below $403 \mathrm{eV}$ are assigned to unoccupied $\mathrm{N} 2 \mathrm{p}$ states hybridized with Ti $3 \mathrm{~d}$ orbitals in $\operatorname{TiN}_{\mathrm{x}}$, and the features between 403 and $415 \mathrm{eV}$ to unoccupied $\mathrm{N}_{2 \mathrm{p}}$ states hybridized with Ti 4 sp orbitals resembling the shape of the $\mathrm{O}$ K-edge [38]. Figure $7 \mathrm{cl}$ and $7 \mathrm{c} 2$ shows the absence of nitrogen in the pristine samples. $\mathrm{TiN}_{\mathrm{x}}$ grown at $800^{\circ} \mathrm{C}$ presents a strong $\mathrm{t}_{2 \mathrm{~g}}$ peak as well as a weaker $\mathrm{e}_{\mathrm{g}}$ peak. It is due to the $\mathrm{O} 2 \mathrm{p}$ hybridization with the $\mathrm{e}_{\mathrm{g}}$ orbitals (figure $7 \mathrm{~b} 3$ ) which hinders the formation of stronger coupled $\mathrm{N} 2 \mathrm{p}$ orbitals with $\mathrm{e}_{\mathrm{g}}$ implying that the nitrogen is added mainly to the $\mathrm{Ti}$ interstitially (figure $7 \mathrm{c} 3$ ). Therefore, the doublets are further disrupted compared with samples prepared at higher temperatures suggesting the local bonding environment of this sample is different. After the electrochemical treatment the nitrogen remains residually in the samples prepared at $800^{\circ} \mathrm{C}$ (figure $7 \mathrm{c} 4$ ). Samples prepared at $1100^{\circ} \mathrm{C}$ resemble d-orbital splitting in energy $\left(t_{2 g}\right.$ and $e_{g}$ ) pointing out the formation of hybridized $\mathrm{N} 2 \mathrm{p}$ states with Ti $3 \mathrm{~d}$ (figure 7c5). It implies that the $\mathrm{Ti} \mathrm{e}_{\mathrm{g}}$ orbitals are direced towards the nitrogen showing a stronger coupling with the $\mathrm{N} 2 \mathrm{p}$ states revealing its substitutional character. After the CA control the spectrum is unaltered (figure 7c6) indicating higher corrosion resistance than the samples prepared at lower temperature.

\section{Discussion}

There seems to be no consensus among the reports on the state of the art of doped nitrogen in $\mathrm{N}-\mathrm{TiO}_{2}$ even though it is considered to be in the anionic form $[39,40]$. While some authors argued that the narrowing of the band gap is due to the formation of oxygen vacancies $[41,42]$ other groups related this effects to the substitution the oxygen by nitrogen [14]. XPS probes the core level binding energies of the constituent species, and the value of the binding energy is a reflection of the valence state and charge density around of the atoms. Finding a solution requires the interpretation of NEXAFS which can provided details about the electronic structure determining the LUMO orbitals around the parent atom. The formation of differently incorporated nitrogen species depends strongly in the sample preparation temperature. Consequently, as the nitrogen is incorporated in the structure it drastically effects its stability as the electrochemical tests proved. The XPS measurement of the samples produced by CVD of $\mathrm{NH}_{3}$ at different temperatures indicated the formation of different species depending strongly on preparation temperature. In principle, nitrogen could be either at the substitutional positions of the lattice or embedded in the interstitial positions. With this as a starting point, the incorporation of nitrogen atoms into the lattice was investigated with XPS and NEXAFS spectroscopies.

It was found that at $800^{\circ} \mathrm{C}$, the nitrogen is incorporated in the form of $\mathrm{TiO}_{\mathrm{x}-2} \mathrm{~N}_{\mathrm{x}}$ or absorbed as $\mathrm{NO}_{\mathrm{x}}$ species. It is corroborated by the inclusion of a strong $\mathrm{O} 1 \mathrm{~s} \mathrm{XP}$ peak at $533.3 \mathrm{eV}$ associated to $\mathrm{NO}_{\mathrm{x}}$ species and another peak at $531.4 \mathrm{eV}$ related to the $\mathrm{TiO}_{\mathrm{x}-2} \mathrm{~N}_{\mathrm{x}}$ species. They are directly associated with the peaks at $400.5 \mathrm{eV}$ and $396.5 \mathrm{eV}$ in the $\mathrm{N}_{1 \mathrm{~s}}$ spectra. NEXAFS measurements proved that the incorporation of nitrogen in the titanium structure is predominantly interstitial as the stronger $t_{2 g}$ at the $\mathrm{N} \mathrm{K}$-edge indicated. The incorporation of nitrogen at $800^{\circ} \mathrm{C}$ from $\mathrm{NH}_{3}$ yields doping indicated by the narrowing of the gap referred to the Fermi level possition. However, the incorporated nitrogen suffers from a lack of stability in acidic environment as the $\mathrm{O}$ and $\mathrm{N} \mathrm{K}$-edges spectra indicated. The species associated with TiOx increased after the electrochemical test as the $\mathrm{O} 1 \mathrm{~s}$ spectrum shows (peak at $530.6 \mathrm{eV}$ ). 
Meanwhile, in samples nitrified at higher temperature the nitrogen is incorporated mainly substitutionally as shown the intense $e_{g}$ peak in the $\mathrm{N}$ K-edge spectrum. Furthermore, it is clear that the Ti $2 p$ XP spectra present a reduction of $\mathrm{Ti}^{4+}$ states and an increase in the $\mathrm{Ti}^{3+}$ which supports the fact that the $\mathrm{N}$ substitutes the oxygen in the lattice. The electrochemical test reveals that $\mathrm{TiN}_{\mathrm{x}}$ produced from $\mathrm{NH}_{3}$ at higher temperatures is more stable as the unaltered $\mathrm{N} \mathrm{K}$-edge NEXAFS spectrum indicated. Only a portion of the $\mathrm{TiN}_{\mathrm{x}}$ is converted into $\mathrm{TiO}_{\mathrm{x}-2} \mathrm{~N}_{\mathrm{x}}$ as the slightly reduction in the $\mathrm{e}_{\mathrm{g}}$ peak intensity indicated and the XPS corroborated (peak at $396.5 \mathrm{eV}$ ). Thus, the higher rate of electrochemical oxidation to form the inert nature and the passive surface are the better proposed model for samples nitrified at higher temperature. Finally, valence band measurements suggested narrower gap than in samples nitrified at lower temperature. After the electrochemical tests, the oxidation explains the broader gap observed in the nitrified samples.

\section{Conclusions}

The interrelationships between the nitrogen incorporation, the chemical nature and the location of $\mathrm{N}$ in the $\mathrm{TiO}_{2}$ lattice was discussed in terms of a combination of XPS and NEXAFS measurements of samples prepared from CVD of ammonia at different temperatures. The nitrogen is incorporated into the lattice as interstitial or substitutional which depends strongly on the temperature and present different stabilities under electrochemical conditions which affect drastically the corrosion resistance. The samples grown at low temperature induce doping but suffer from low stability in acidic media while the samples nitrified at higher temperature yield higher corrosion resistance. The electrochemical stability depends strongly on the nature of the incorporated nitrogen (interstitial or substitutional) where the $\mathrm{TiN}_{\mathrm{x}}$ electronic structure is described by the hybridization of the $\mathrm{N} 2 \mathrm{p}$ with the Ti $3 \mathrm{~d}$ orbitals. At low temperature the $\mathrm{N}$ p-orbitals are more likely to hybridize with the $\mathrm{Ti}_{3 \mathrm{~d}}-\mathrm{t}_{2 \mathrm{~g}}$ orbitals indicating an interstitial nature. Meanwhile, samples nitrified at higher temperature show $\mathrm{N} 2 \mathrm{p}$ hybridization with the $\mathrm{Ti}_{3 \mathrm{~d}}-\mathrm{e}_{\mathrm{g}}$ orbitals revealing the nitrogen substitutional nature. This finding provides clear understanding in the corrosion resistance and doping effect of nitrogen incorporation in titanium which dominates the electrochemical performance of the electrode.

\section{Acknowledgements:}

We thank to the staff at BESSY of the HZB for supporting the operation. HZB is acknowledged for granting beamtime at the ISSIS endstation under proposal \#14201159. We thank Ministry of Education and Science of the Russian Federation (agreement \#14.616.21.0007) and Bundesministerium für Bildung und Forschung (project \#05K2014) for financial support in the framework of joint Russian-German research project "SYnchrotron and NEutron STudies for Energy Storage (SYNESTESia)". JV gratefully acknowledges financial support from the Alexander von Humboldt foundation. The Advanced Light Source is supported by the Director, Office of Science, Office of Basic Energy Sciences, of the U.S. Department of Energy under Contract No. DE-AC02-05CH11231. We thanks Dr. Bejamin Johnson for helping during the manuscript preparation.

\section{References}

[1] B. Dunn, H. Kamath, J. M. Tarascon, Science 334 (2011) 928.

[2] A. Züttel, A. Borgschulte, L. Schlapbach, Hydrogen as a future energy carrier. John Wiley \& Sons 2011. 
[3] Z. Yang, J. Zhang, M. C. Kintner-Meyer, X. Lu, D. Choi, J. P. Lemmon, J. Liu, Chemical Reviews 111 (2011) 3577.

[4] J. P. Barton, D. G. Infield, IEEE Transactions 19 (2004) 441.

[5] J. A. Turner, Science 285 (1999) 687.

[6] A. Marshall, B. Børresen, G. Hagen, M. Tsypkin, R. Tunold, Energy 32 (2007) 431.

[7] S. Stucki, G. G. Scherer, S. Schlagowski, E. Fischer, Journal of applied electrochemistry, 28 (1998) 1041.

[8] B. Paul, J. Andrews, International journal of hydrogen energy, 33 (2008) 490.

[9] S. A. Grigoriev, P. Millet, V. N. Fateev, Journal of Power Sources, 177 (2008) 281.

[10] A. V. Nikiforov, I. M. Petrushina, E. Christensen, A. L. Tomás-García, N. J. Bjerrum, International Journal of Hydrogen Energy, 36 (2011) 111.

[11] M. Palcut, L. Mikkelsen, K. Neufeld, M. Chen, R. Knibbe, P. V. Hendriksen, Corrosion Science, 52 (2010) 3309.

[12] S. Dutta, International Journal of Hydrogen Energy, 15 (1990) 379.

[13] M. Pourbaix, Corrosion Science, 14 (1974) 25.

[14] R. Asahi, T. Morikawa, T. Ohwaki, K. Aoki, Y. Taga, Science, 293 (2001) 269.

[15] H. Irie, Y. Watanabe, K. Hashimoto, The Journal of Physical Chemistry B, 107 (2003) 5483.

[16] H. Chen, A. Nambu, W. Wen, J. Graciani, Z. Zhong, J. C. Hanson, E. Fujita,J. A. Rodriguez, The Journal of Physical Chemistry C, 111 (2007) 1366.

[17] B. Avasarala, P. Haldar, Electrochimica Acta, 55 (2010) 9024.

[18] S. J. Stewart, M. Fernández-García, C. Belver, B. S. Mun, F. G. Requejo, The Journal of Physical Chemistry B, 110 (2006) 16482.

[19] C. S. Gopinath, The Journal of Physical Chemistry B, 110 (2006) 7079.

[20] X. Chen, C. Burda, The Journal of Physical Chemistry B, 108 (2004) 15446.

[21] E. György, A. Perez del Pino, P. Serra, J. L. Morenza, Surface and Coatings Technology, 173 (2003) 265.

[22] M. Sathish, B. Viswanathan, R. P. Viswanath, C. S. Gopinath, Chemistry of materials, 17 (2005) 6349.

[23] M. MansoobáKhan, M. OmaisháAnsari, D. HungáHan, M. HwanáCho, Journal of Materials Chemistry A, 2 (2014) 637.

[24] N. C. Saha, H. G. Tompkins, Journal of Applied Physics, 72 (1992) 3072.

[25] X. Chen, P. A. Glans, X. Qiu, S. Dayal, W. D. Jennings, K. E. Smith, C. Burda, J. Guo, Journal of Electron Spectroscopy and Related Phenomena, 162 (2008) 67.

[26] P. Stefanov, M. Shipochka, P. Stefchev, Z. Raicheva, V. Lazarova, L. Spassov, Journal of Physics: Conference Series, 100 (2008) 012039.

[27] P. A. van Hal, M. M. Wienk, J. M. Kroon, W. J. Verhees, L. H. Slooff, W. J. van Gennip, P. Jonkheijm, R. A. Janssen, Advanced Materials, 15 (2003) 118.

[28] M. H. Chan, F. H. Lu, Thin Solid Films, 518 (2009) 1369.

[29] Y. Wang, C. Feng, M. Zhang, J. Yang, Z. Zhang, Applied Catalysis B: Environmental, 100 (2010) 84.

[30] M. Batzill, E. H. Morales, U. Diebold, Physical review letters, 96 (2006) 026103.

[31] X. Chen, L. Liu, Z. Liu, M. A. Marcus, W. C. Wang, N. A. Oyler, M. E. Grass, B. Mao, P. A. Glans, P. Y. Yu, J. Guo, S. S. Mao, Scientific reports, 3 (2013).

[32] J. H. Van Vleck, Physical Review, 41 (1932) 208.

[33] V. S. Lusvardi, M. A. Barteau, J. G. Chen, Jr. J. Eng, B. Frühberger, A. Teplyakov, Surface Science, 397 (1998) 237.

[34] G. Drera, L. Sangaletti, F. Bondino, M. Malvestuto, L. Malavasi, Y. Diaz-Fernandez, S. Dash, M. C. Mozzati, P. Galinetto, Journal of Physics: Condensed Matter, 25 (2013) 075502.

[35] T. Hiratoko, A. Yoshiasa, T. Nakatani, M. Okube, A. Nakatsuka, K. Sugiyama, Journal of synchrotron radiation, 20 (2013) 0. 
[36] L. D. Finkelstein, E. I. Zabolotzky, M. A. Korotin, S. N. Shamin, S. M. Butorin, E. Z. Kurmaev, J. Nordgren, X-Ray Spectrometry, 3 (2002) 414.

[37] A. Braun, K. K. Akurati, G. Fortunato, F. A. Reifler, A. Ritter, A. Harvey, A. Vital, T. Graule, The Journal of Physical Chemistry C, 114 (2009) 516.

[38] J. L. Endrino, C. Århammar, A. Gutiérrez, R. Gago, D. Horwat, L Soriano, G. F. Rabinovich, D. Martin y Marero, J. Guo, J.-E. Rubensson, Andersson, Acta Materialia, 59 (2011) 6287.

[39] B. Viswanathan, K. R. Krishanmurthy, International Journal of Photoenergy, 2012 (2012).

[40] L. Lo Presti, M. Ceotto, F. Spadavecchia, G. Cappelletti, D. Meroni, R. G. Acres, S. Ardizzone, The Journal of Physical Chemistry C, 118 (2014) 4797.

[41] E. Finazzi, C. Di Valentin, A. Selloni, G. J. Pacchioni, Phys Chem. C, 111 (2007) 9275.

[42] S. Livraghi, M. C. Paganini, E. Giamello, A. Selloni, C. Di Valentin, G. J. Pacchioni, Am. Chem. Soc., 128 (2006) 15666.

[43] T. Morikawa, R. Asahi, T. Ohwaki, K. Aoki, Y Taga , Japan. J. Appl. Phys. Lett., 40 (2005) L561.

[44] L. Y. Lee, J. Park, J. H. d Cho, Appl. Phys. Lett., 87 (2005) 011904.

[45] X. B. Chen, Y. B. Lou, A. C. S. Samia, C. Burda, J. L. Gole, Adv. Funct. Mater., 15 (2005), 41.

[46] Wu P G, Ma C H and Shang J K, Appl. Phys. A-Mater. Sci. Process., 81 (2005) 1411.

[47] Y. Suda, H. Kawasaki, T. Ueda, T. Ohshima, Thin Solid Films, 475 (2005) 337. 


\section{Exploring the incorporation of nitrogen in titanium and its influence on the electrochemical corrosion resistance in acidic media}

J.J. Velasco-Velez ${ }^{1 *}$, B. Davaasuren ${ }^{2}$, M. Scherzer ${ }^{2}$, S. Cap ${ }^{2}$, M. Willinger ${ }^{1}$, J.H. Guo ${ }^{3}$, R. Schlögl ${ }^{1,2}$, and A. Knop-Gericke ${ }^{2}$

${ }^{1}$ Max Planck Institute for Chemical Energy Conversion, Mülheim 45470, Germany ${ }^{2}$ Fritz-Haber-Institute of the Max Planck Society, Berlin 14195, Germany

${ }^{3}$ The Advance Light Source, Lawrence Berkeley National Laboratory, Berkeley CA 94720, USA

*Corresponding author: velasco@fhi-berlin.mpg.de

Table 1: Summary of associated BE and chemical state for Ti 2p, O 1s and N 1s XP spectra.

\begin{tabular}{|cc|c|c|c|c|}
\hline Orbital & $\mathrm{TiO}_{\mathrm{x}} / \mathrm{T}^{4+}$ & $\mathrm{TiO}_{\mathrm{x}-2} \mathrm{~N}_{\mathrm{x}}$ & $\mathrm{TiN}_{\mathrm{x}} / \mathrm{Ti}^{3+}$ & $\mathrm{O}_{2} / \mathrm{H}_{2} \mathrm{O}$ & $\mathrm{NO}_{\mathrm{x}}$ \\
$\mathrm{Ti} 2 \mathrm{p}$ & $459.2 \mathrm{eV}$ & $457.2 \mathrm{eV}$ & $454.9 \mathrm{eV}$ & & \\
\hline $\mathrm{O} 1 \mathrm{~s}$ & $530.6 \mathrm{eV}$ & $531.4 \mathrm{eV}$ & & $532.5 \mathrm{eV}$ & $533.3 \mathrm{eV}$ \\
\hline $\mathrm{N} 1 \mathrm{~s}$ & & $396.5 \mathrm{eV}$ & $397.0 \mathrm{eV}$ & & $400.5 \mathrm{eV}$ \\
\hline
\end{tabular}
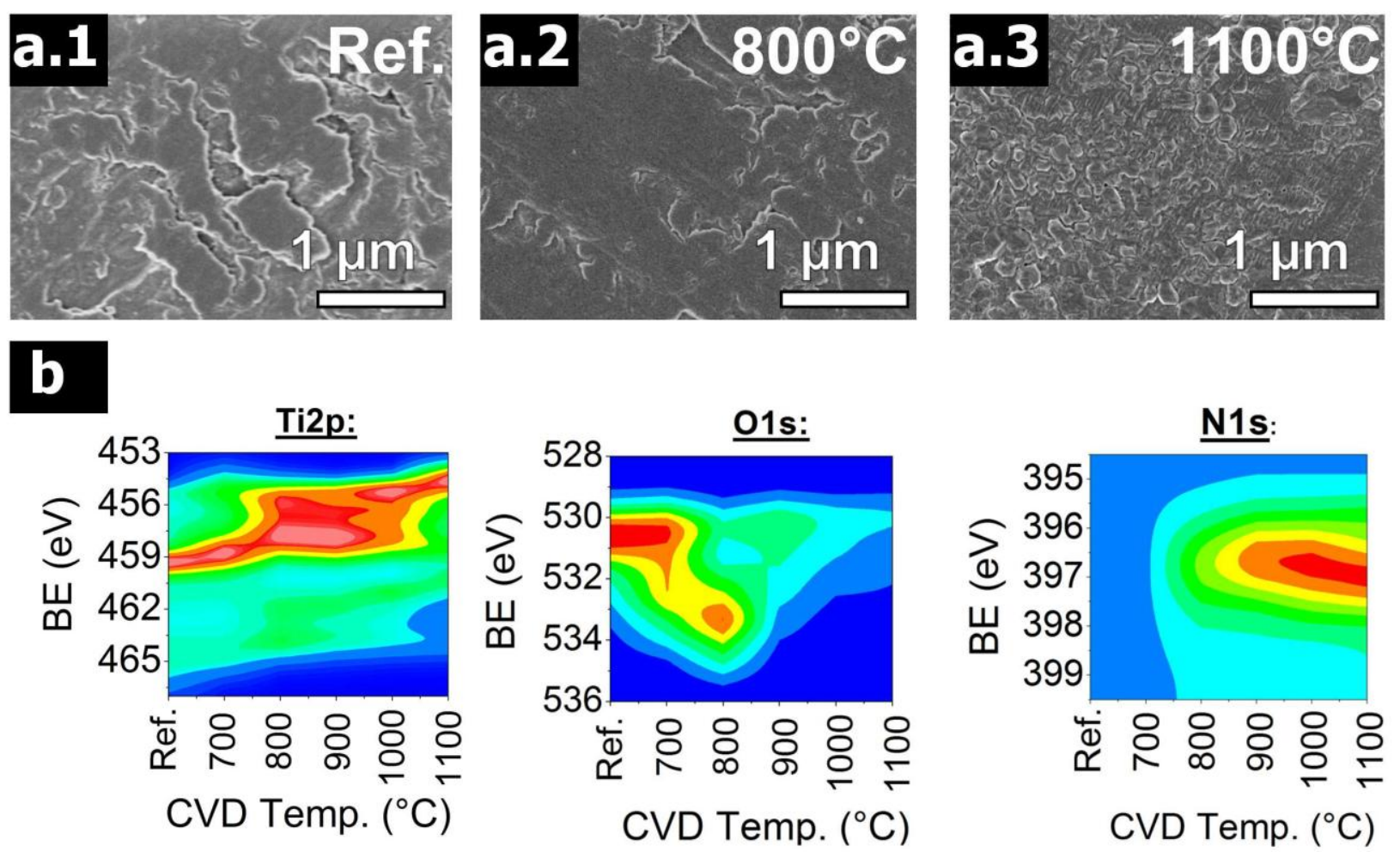

Figure 1: a) SEM pictures of the CVD of $\mathrm{TiN}_{\mathrm{x}}$ process fabricated at different temperature. b) Ti $2 p, O$ $1 \mathrm{~s}$ and $\mathrm{N} 1 \mathrm{~s}$ XP spectra vs. temperature. 

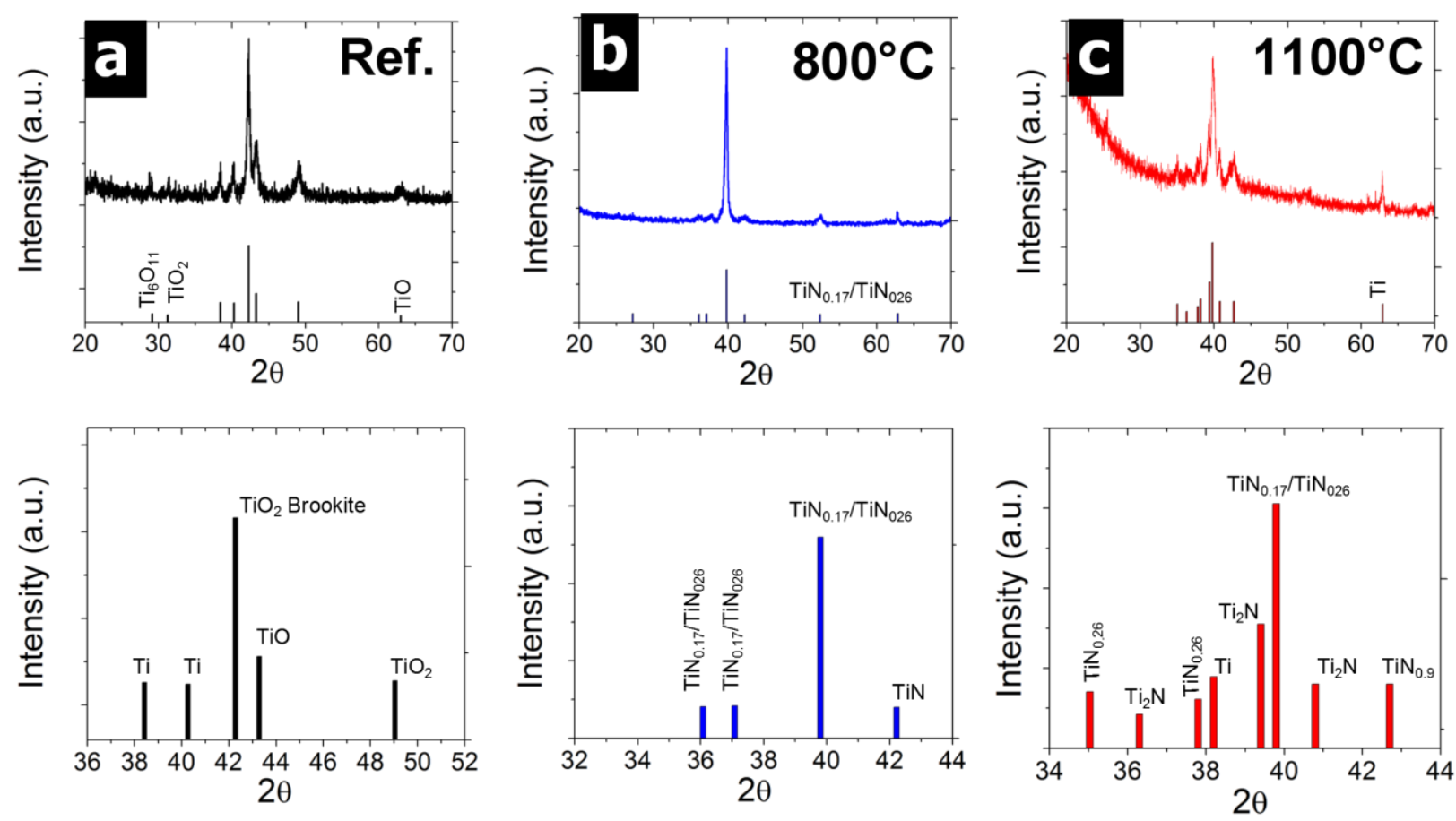

Figure 2: XRD spectra (top) and species inset (bottom) of a) pristine Ti samples b) nitrified from $\mathrm{NH}_{3}$ at $800^{\circ} \mathrm{C}$ and c) at $1100^{\circ} \mathrm{C}$.
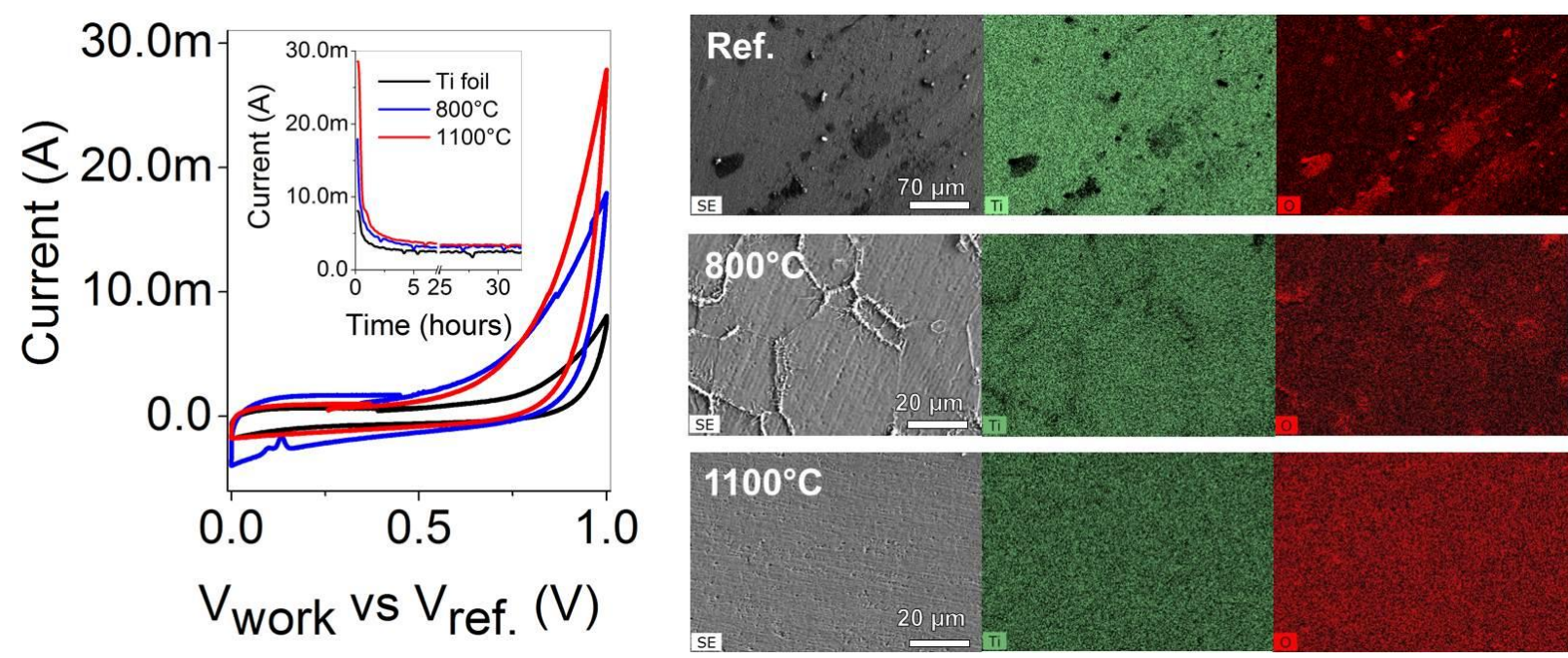

Figure 3: $\mathrm{CA}$ measurements in $1 \mathrm{M}$ of $\mathrm{HClO}_{4}$ during $\sim 32$ hours and the effect in the film shows by SEM/EDX after the electrochemical stress test. 

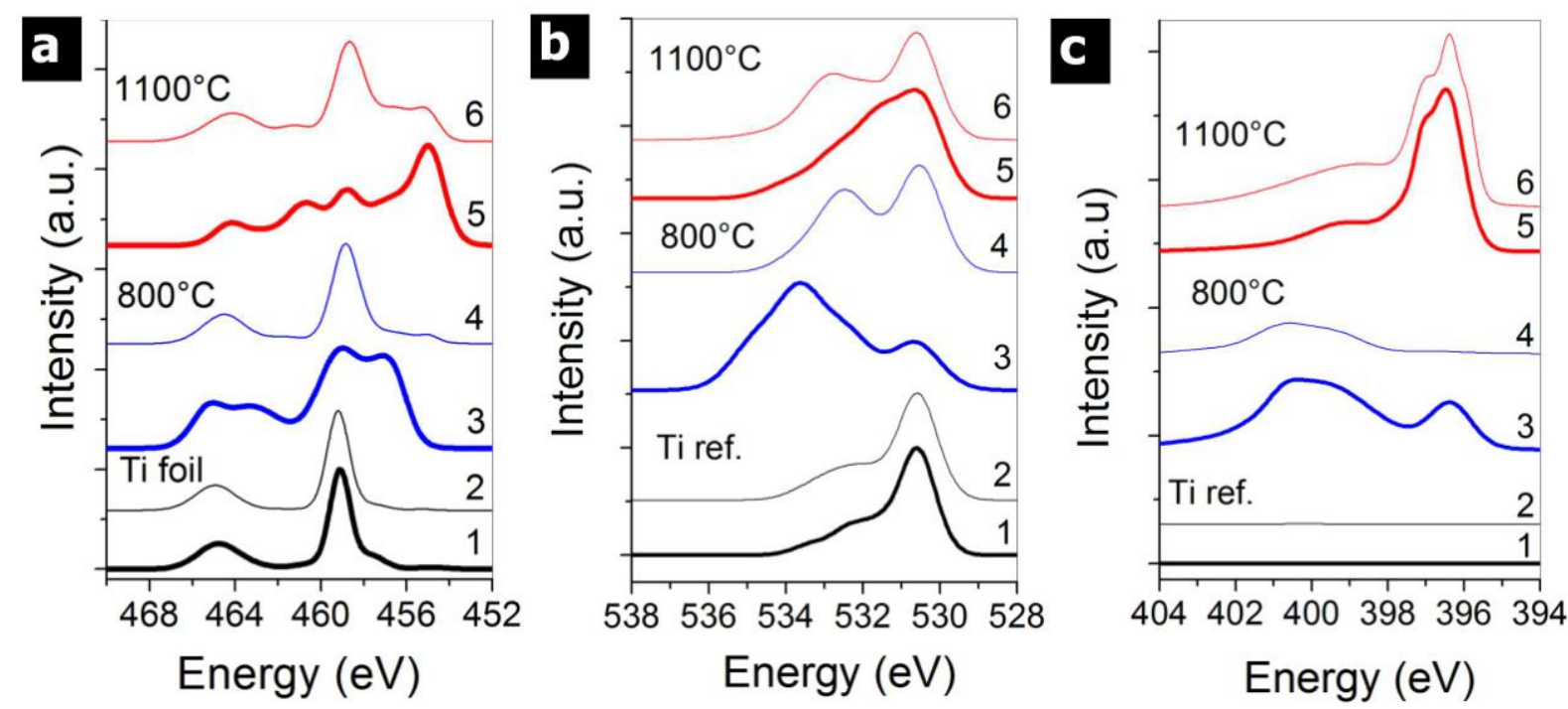

Figure 4: XPS measurements before and after electrochemical stress test: a) Ti 2p, b) O 1s and c) N $1 \mathrm{~s}$.
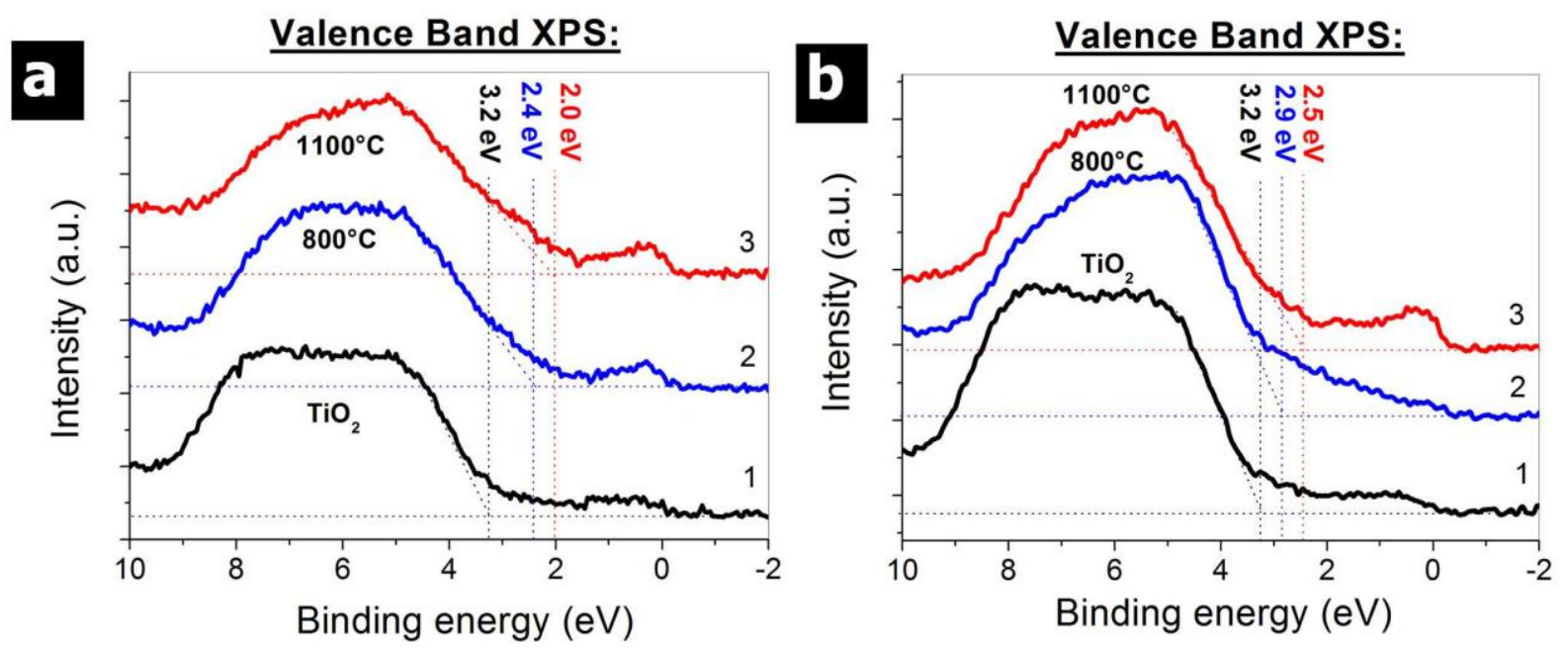

Figure 5: a) Valence band spectra before the electrochemical stress test. b) Valence band spectra after the electrochemical stress test. 

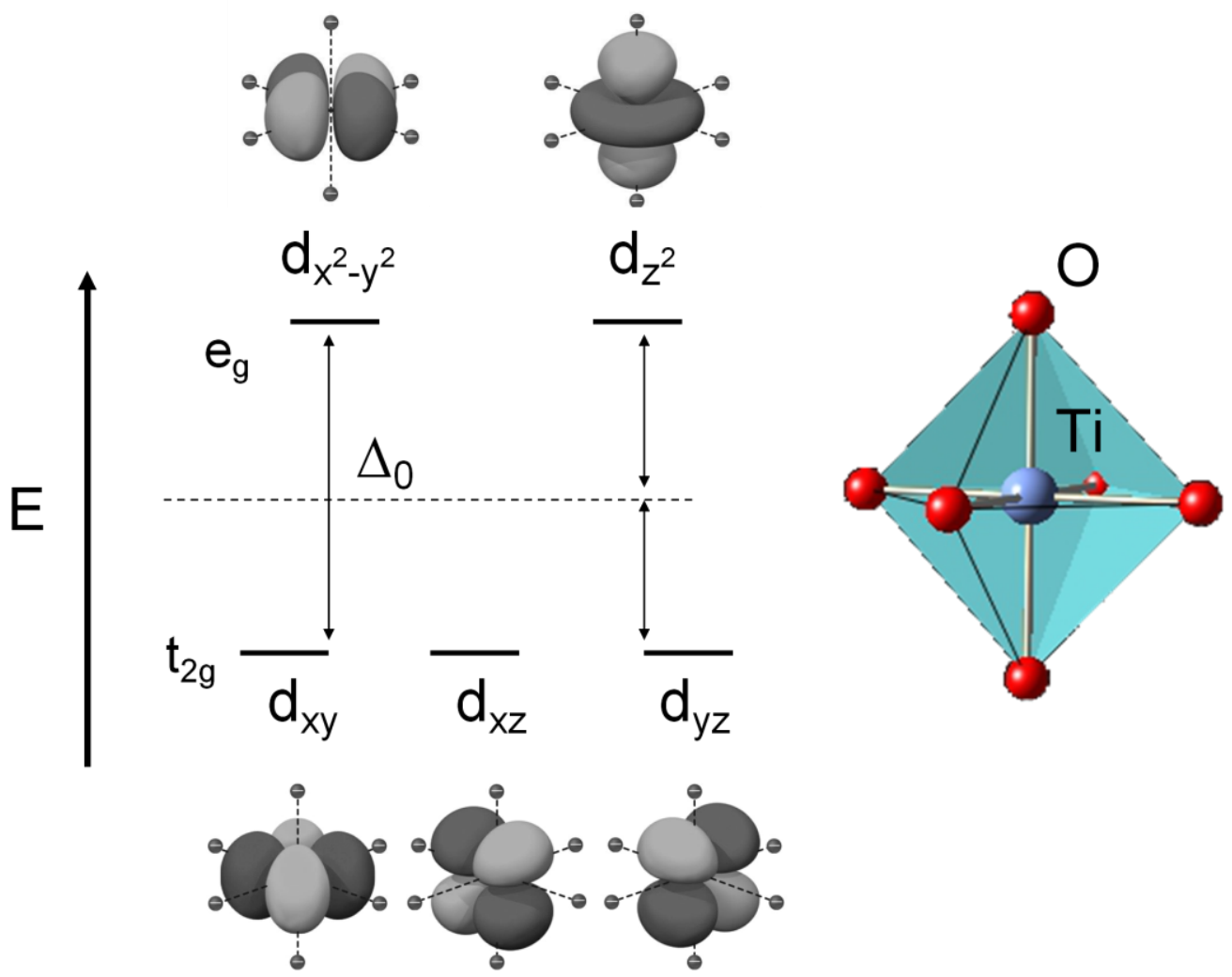

Figure 6: Schematic of the d-orbitals splitting in energy $t_{2 g}$ and $e_{g}$.
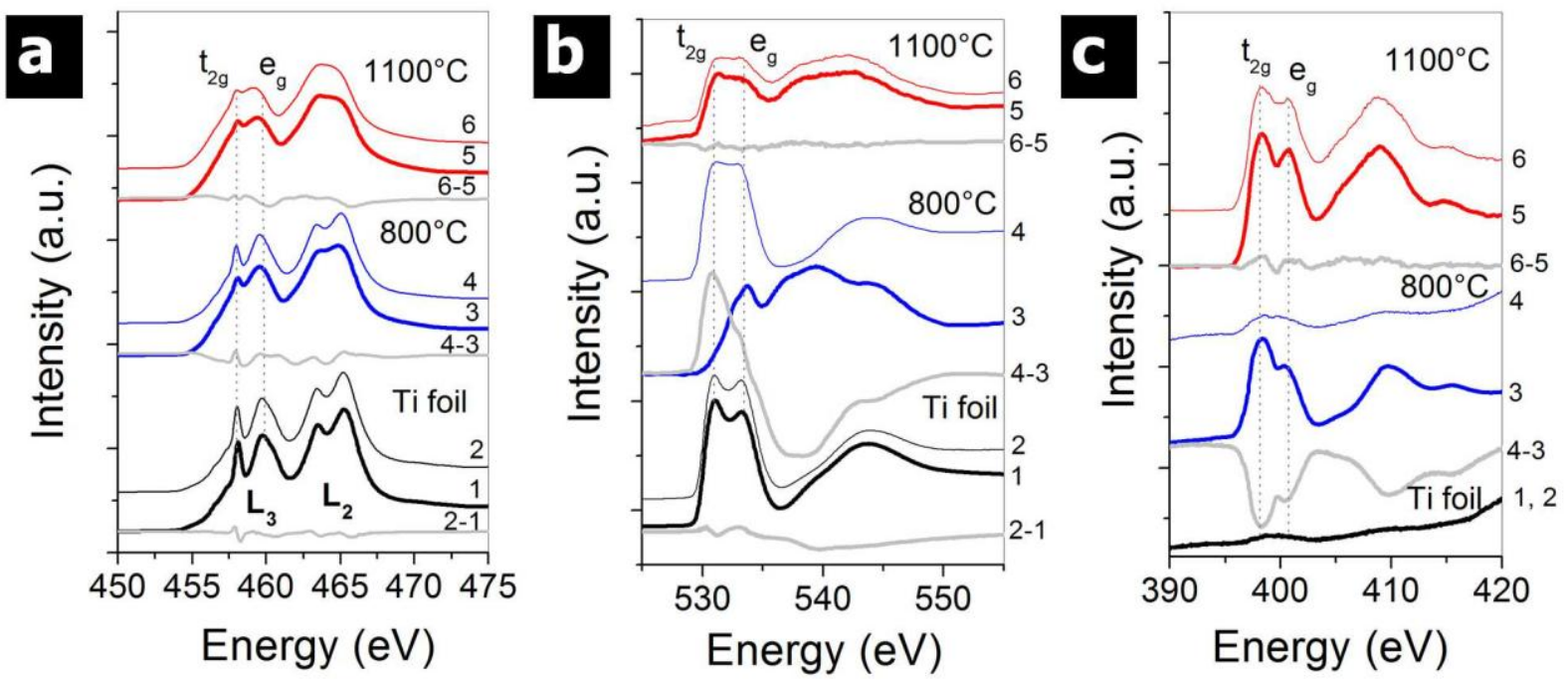

Figure 7: NEXAFS measurements before and after electrochemical stress test: a) Ti L-edge, b) $\mathrm{O}$ and c) $\mathrm{N}$ K-edges. 